Published in final edited form as:

J Mol Biol. 2012 November 09; 423(5): 752-765. doi:10.1016/j.jmb.2012.08.026.

\title{
Crystal structure of the N-terminal domain of Nup358/RanBP2
}

\author{
Susanne A. Kassube ${ }^{2,3}$, Tobias Stuwe ${ }^{1}$, Daniel H. Lin ${ }^{1}$, C. Danielle Antonuk ${ }^{1}$, Johanna \\ Napetschnig ${ }^{2,4}$, Günter Blobel2,", and André Hoelz ${ }^{1,2,{ }^{*}}$ \\ ${ }^{1}$ Division of Chemistry and Chemical Engineering, California Institute of Technology, 1200 East \\ California Boulevard, Pasadena, CA 91125, USA \\ ${ }^{2}$ Laboratory of Cell Biology, Howard Hughes Medical Institute, The Rockefeller University, 1230 \\ York Avenue, New York, NY 10065, USA
}

\begin{abstract}
Key steps in mRNA export are the nuclear assembly of messenger ribonucleoprotein particles (mRNPs), the translocation of mRNPs through the nuclear pore complex (NPC), and the mRNP remodeling events at the cytoplasmic side of the NPC. Nup358/RanBP2 is a constituent of the cytoplasmic filaments of the NPC specific to higher eukaryotes and provides a multitude of binding sites for the nucleocytoplasmic transport machinery. Here, we present the crystal structure of the Nup358 N-terminal domain (NTD) at 0.95 - ̊ resolution. The structure reveals an a-helical domain that harbors three central tetratricopeptide repeats (TPR), flanked on each side by an additional solvating amphipathic a helix. Overall, the NTD adopts an unusual extended conformation that lacks the characteristic peptide-binding groove observed in canonical TPR domains. Strikingly, the vast majority of the NTD surface exhibits an evolutionarily conserved, positive electrostatic potential, and we demonstrate that the NTD possesses the capability to bind single-stranded RNA in solution. Together, these data suggest that the NTD contributes to mRNP remodeling events at the cytoplasmic face of the NPC.
\end{abstract}

\section{Keywords}

X-ray crystallography; tetratricopeptide repeat (TPR); fluorescence localization microscopy; Nuclear Pore Complex (NPC); RNA binding protein

\section{Introduction}

The bidirectional transport of macromolecules between the nucleus and cytoplasm is mediated solely by nuclear pore complexes (NPCs). NPCs are composed of $\approx 30$ different proteins termed nucleoporins (nups) and are among the largest proteinaceous assemblies in the eukaryotic cell ( $\approx 60 \mathrm{MDa}$ in yeast, $\approx 120 \mathrm{MDa}$ in vertebrates). ${ }^{1}$ In addition to its central

\footnotetext{
"Correspondence: blobel@ rockefeller.edu (G.B.), hoelz@ caltech.edu (A.H.).

3 Present address: Biophysics Graduate Group, University of California, Berkeley, Berkeley, CA 94720, USA

${ }^{4}$ Present address: Department of Biochemistry, Weill Medical College of Cornell University, 1300 York Avenue, New York, NY 10021, USA

ACCESSION NUMBERS

The atomic coordinates and structure factors of the H. sapiens, and P. troglodytes Nup $358^{\mathrm{NTD}}$ have been deposited in the Protein Data Bank under accession codes 4GA0, 4GA1 and 4GA2, respectively.
} 
role in nucleocytoplasmic transport, the NPC has various other important functions, such as chromatin organization, regulation of transcription, and DNA repair. ${ }^{1}$

NPCs consist of a doughnut-shaped symmetric core that is decorated asymmetrically by nups that form the cytoplasmic filaments and a nuclear "basket" structure. ${ }^{1}$ Structural studies have established an evolutionary connection between the symmetric core of the NPC and membrane coats. ${ }^{2-7}$ The cytoplasmic filaments provide the binding sites for transportfactor ${ }^{\circ}$ argo complexes and are composed of four proteins in vertebrates, CG1, Nup88, Nup214/CAN, and Nup358/RANBP2. ${ }^{1,8}$ Nup358 has no obvious homolog in yeast and is a unique component of NPCs of higher eukaryotes. ${ }^{9,10}$

Over the last decade, key steps in the export of mRNA from the nucleus to the cytoplasm have been identified and linked to the cytoplasmic filament nups. ${ }^{8,11}$ Nup88 is required for the recruitment of Nup98, an essential component of the export complexes of both ribosomal and messenger RNAs. ${ }^{12-15}$ Nup214/CAN binds the DEAD-box helicase Ddx19/hDbp5, an mRNA export factor that is involved in mRNP remodeling events at the cytoplasmic face of the NPC. ${ }^{16-18}$ Nup358 provides binding sites for not only the heterodimeric mRNA export receptor NXF1 $\bullet 15^{19}$, but also SUMOylated RanGAP1 and the export factor CRM1. ${ }^{20,21}$ In addition to its function in nucleocytoplasmic transport, Nup358 relocates to the kinetochore during mitosis and plays various other crucial roles during mitosis, such as facilitating spindle formation and chromosome congression and segregation. ${ }^{22,23}$

A striking link exists between the nups that constitute or interact with the cytoplasmic filaments and neoplastic disease. ${ }^{24,25}$ Chromosomal translocations involving Nup98 have been identified in patients with acute myelogenous leukemia, myelodysplastic syndrome, chronic myelogenous leukemia, and $\mathrm{T}$ cell acute lymphoblastic leukemia. ${ }^{24}$ Expression of Nup88 is strongly upregulated in late-stage breast cancer and is used as a prognostic marker. ${ }^{26}$ Similarly, the expression of Nup214/CAN and Nup358 is upregulated in plasma cells from patients with multiple myeloma, emphasizing the importance of these nups in tumorigenesis. ${ }^{27}$ Fusions of Nup214/CAN and Nup358 are involved in leukemogenesis, particularly acute myelogenous leukemia. ${ }^{28,29}$ Moreover, mutations in Nup358 have been linked to the susceptibility of otherwise healthy children to acute necrotizing encephalopathy following common viral infections, such as influenza. ${ }^{30}$

The polypeptide chain of Nup358 contains 3,224 residues and can approximately be divided into several distinct regions: an N-terminal $~ 830$-residue a-helical region followed by four RanGTP-binding domains, eight consecutive zinc finger motifs, an E3 ligase domain, and a C-terminal cyclophilin A homology domain (Fig. 1a). ${ }^{9,10}$ These domains are connected by predicted unstructured regions containing phenylalanine-glycine (FG) repeats, which constitute the docking sites for mobile transport factors. ${ }^{1,11,31}$ So far only small fragments, the E3 ligase domain and two Ran binding domains, of Nup358 have been structurally characterized.

In order to deepen our understanding of the structural organization of Nup358, we have determined the crystal structure of the N-terminal domain (NTD) of Nup358 at $0.95-\AA$ resolution. The structure reveals an a-helical domain with the overall shape of an extended 
sheet with a right-handed twist that is primarily composed of three non-canonical tetratricopeptide repeats (TPRs). Strikingly, the surface of Nup358 ${ }^{\mathrm{NTD}}$ is highly positively charged and we demonstrate biochemically that it binds to single-stranded RNA. We show that Nup358 $8^{\mathrm{NTD}}$ is not required for nuclear envelope localization of Nup358 in vivo. These results suggest that Nup358 $8^{\mathrm{NTD}}$ plays a role in RNA export events that occur at the cytoplasmic face of the NPC.

\section{Results}

\section{Structure determination}

We designed a series of expression constructs for the approximately 830-residue $\mathrm{N}$-terminal region of human Nup358, which is predicted to be entirely a-helical. We identified a stable fragment consisting of residues 1 to 145, which we termed the Nup358 N-terminal domain (Nup358 ${ }^{\mathrm{NTD}}$ ) (Fig. 1a). Crystals of the human Nup358 ${ }^{\mathrm{NTD}}$ were non-merohedrally twinned, preventing experimental phasing efforts. To overcome the inherent twinning of the crystals, we purified the NTDs of various homologous species. The Pan troglodytes Nup358 NTD is monomeric in solution with a molecular mass of $17.4 \mathrm{kDa}$ (theoretical $17.1 \mathrm{kDa}$ ), as determined by size-exclusion chromatography coupled with multiangle light scattering (Fig. 1b). Crystals of $P$. troglodytes Nup $358^{\mathrm{NTD}}$ belong to the orthorhombic space group $\mathrm{P} 2{ }_{1} 2_{1} 2$ with one molecule in the asymmetric unit, and yielded diffraction data with only a small twinning fraction. The structure of $P$. troglodytes Nup $358^{\mathrm{NTD}}$ was solved by singlewavelength anomalous dispersion (SAD) using X-ray diffraction data collected from crystals of a selenomethionine-labeled mutant in which three additional methionines were incorporated with the aid of a multi-species sequence alignment (Fig. 2). The structure of $P$. troglodytes Nup358 ${ }^{\mathrm{NTD}}$ was refined to 0.95 - $\AA$ resolution with $\mathrm{R}_{\text {work }}$ and $\mathrm{R}_{\text {free }}$ values of $18.2 \%$ and $20.9 \%$, respectively. Moreover, we were able to solve the structure of the human Nup $358^{\mathrm{NTD}}$ by molecular replacement using the $P$. troglodytes $\mathrm{Nup} 358^{\mathrm{NTD}}$ as the search model and refined the structure to $1.15 \AA$ resolution with $\mathrm{R}_{\mathrm{work}}$ and $\mathrm{R}_{\text {free }}$ values of $23.6 \%$ and $25.6 \%$, respectively. For details of the data collection and refinement statistics, see Table 1. The structures of the P. troglodytes and human Nup358 $8^{\mathrm{NTD}}$ adopt the same fold and align with a root-mean square deviation (RMSD) of $0.27 \AA$ over all atoms. Due to the higher quality of the data, we will focus our structural analysis on the P. troglodytes Nup $358^{\mathrm{NTD}}$.

\section{Architectural overview and topology}

The polypeptide chain of Nup $358^{\mathrm{NTD}}$ folds into a slightly curved, right-handed twisted sheet with approximate dimensions of $55 \AA \times 20 \AA \times 25 \AA$, which consists of eight a-helices, a A$\mathrm{aH}$, that are stacked in a zigzag arrangement (Fig. 3a and Fig. S1). The majority of the domain is formed by three central tetratricopeptide repeats (TPRs), $a B-a C$ (TPR1), $a D-a E$ (TPR2), and $a \mathrm{~F}-\mathrm{aG}$ (TPR3), that are arranged in tandem and are capped at the N- and Cterminal ends by additional solvating amphipathic ahelices ( $\mathrm{AA}$ and $\mathrm{aH}$ ) (Fig. 3a, b). The eight ahelices of the domain segregate into inner $(\mathrm{aB}, \mathrm{aD}, \mathrm{aF}$, and $\mathrm{aH})$ and outer $(\mathrm{aA}, \mathrm{aC}$, $\mathrm{aE}$, and $\mathrm{aG}$ ) layers, which dominate the concave and convex surfaces, respectively (Fig. 3 and Fig. 4a). Overall, Nup358 ${ }^{\text {NTD }}$ displays an unusual, elongated topology with a righthanded twist of $\approx 80^{\circ}$ between the first a helix $(\mathrm{aA})$ and last a helix $(\mathrm{aH})$, resulting in a substantially shallower surface groove compared to canonical TPR proteins (see below). 


\section{TPRs of the Nup358 ${ }^{\mathrm{NTD}}$}

The canonical TPR motif consists of $\approx 34$ residues that fold into a pair of anti-parallel ahelices. ${ }^{32}$ While the TPR sequence motif is degenerate in nature, a conserved pattern of small and large hydrophobic signature residues with the consensus sequence $\mathrm{W}_{4} \mathrm{G}_{8} \mathrm{Y}_{11} \mathrm{G}_{15} \mathrm{Y}_{17} \mathrm{~A}_{20} \mathrm{Y}_{24} \mathrm{~A}_{27} \mathrm{P}_{32}$ can be identified ${ }^{33}$. These residues form a network of packing interactions between and within TPR repeats. Canonical TPR proteins contain 3-16 TPRs arranged in tandem. Adjacent ahelices are typically rotated counterclockwise with an angle of $24^{\circ}$. As a consequence of this regular stacking, the a helices adopt a right-handed super-helical conformation.

The Nup $358^{\mathrm{NTD}}$ core is composed of three TPRs that superimpose with an RMSD of $\approx 1.2$ $\AA$ over $34 \mathrm{Ca}$ atoms (Fig. 5). This TPR core is capped by additional N- and C-terminal amphipathic ahelices, $\mathrm{aA}$ and $\mathrm{aH}$. These solvating ahelices cover the terminal hydrophobic residues of TPR 1 and TPR 3 and expose polar residues to the outside of the domain. Notably, the angles between a helices of the same TPR and between adjacent TPRs both differ markedly from the canonical $\approx 24^{\circ}$ angle: ${ }^{32}$ the angles between $\mathrm{aA}-\mathrm{aB}\left(16^{\circ}\right)$, aB-aC $\left(15^{\circ}\right)$, $\mathrm{aD}-\mathrm{aE}\left(18^{\circ}\right)$, and $\mathrm{aE}-\mathrm{aF}\left(20^{\circ}\right)$ are smaller, and those between $\mathrm{aC}-\mathrm{aD}\left(28^{\circ}\right), \alpha \mathrm{F}-\mathrm{aG}\left(34^{\circ}\right)$, and $\mathrm{aG}-\mathrm{aH}\left(30^{\circ}\right)$ are larger. This deviation results in the unusual elongated and twisted topology of the Nup358 NTD instead of the regular right-handed solenoid conformation observed in canonical TPR proteins. ${ }^{32}$

Despite the atypical inter-helical angles, the interactions within the three Nup358 ${ }^{\mathrm{NTD}}$ TPRs are mediated mostly by canonical interactions. Similarly, the contacts between the solvating ahelices and their neighboring TPRs are mediated via interactions that resemble those between canonical TPRs. A marked exception to the canonical motif can be found at position 27 in TPR1, where a small, hydrophobic residue is highly conserved in TPRs due to steric restrictions. However, instead of this small residue, a large hydrophobic residue, Tyr52, can be found in TPR1, inducing a sharp $\approx 40^{\circ}$ kink in the neighboring ahelix, $a \mathrm{~B}$. A multi-species sequence alignment reveals that this tyrosine is highly conserved throughout evolution at this position in Nup358 $8^{\mathrm{NTD}}$ (Fig. 2).

\section{Surface properties}

To identify potential protein-protein interaction sites, we analyzed the conservation and the electrostatic potential of the Nup358 $8^{\mathrm{NTD}}$ surface (Fig. 6a, b). With the exception of the Nterminal solvating helix aA whose residues are more variable across species, the surface of the Nup358 $8^{\text {NTD }}$ is highly conserved within higher eukaryotes (Fig. 2). Most of the conserved residues in the three TPRs coincide with TPR signature residues, with the exception of Tyr52 in TPR1, which induces the kink in helix aB (Fig 4a, b). Strikingly, analysis of the electrostatic properties of Nup358 $8^{\mathrm{NTD}}$ reveals that the majority of the surface possesses a highly positive surface potential, while only one side of the molecule is negatively charged, resulting in a segregation of opposing potentials. In addition, two small and essentially invariant hydrophobic regions can be identified on the concave surface of the C-terminal half and on the central elevation of the convex surface. The distinct, positive surface potential is the result of an unusually high and evolutionarily-conserved Lys/Arg content ( $\approx 20 \%)$ that dominates the surface properties of the molecule (Fig. 2 and Fig. 6). The small surface patch 
of negative surface potential is generated exclusively by the solvating, C-terminal helix aH and the intra-repeat loops of the three TPRs (Fig. 6b). Notably, the high content of positively charged residues does not extend to the a-helical region that follows Nup $358^{\mathrm{NTD}}$, supporting the conclusion that the entire $\mathrm{N}$-terminal a-helical region of Nup358 is composed of at least two domains with distinct functions.

\section{Structural comparison}

To investigate whether Nup358 $8^{\mathrm{NTD}}$ may be suitable to mediate interactions with short, yet extended peptide fragments as previously described for other TPR proteins, we compared the structure of Nup $358^{\mathrm{NTD}}$ to those of protein phosphatase 5 (PP5), ${ }^{34}$ the TPR1 domain of Hop in complex with an Hsp70 peptide, ${ }^{35}$ and the superhelical TPR domain of O-linked GlcNAc transferase (OGT) ${ }^{36}$ (Fig. 7). PP5 and Hop contain TPR domains that are of similar size to Nup358 ${ }^{\mathrm{NTD}}$, while OGT is constructed of 11.5 TPRs.

The TPR domain of PP5 consists of three virtually identical, canonical TPR motifs that exhibit a right-handed superhelical conformation with an amphipathic channel at its concave surface that was shown to bind short, extended peptide fragments. ${ }^{34}$ Hop mediates the association between Hsp70 and Hsp90 via C-terminal peptides containing an EEVD motif. Peptide recognition involves the two-carboxylate moieties at the C-terminus of the peptide and conserved lysines and asparagines in all three TPRs that protrude from the concave surface of the domain. ${ }^{35}$ The superhelical TPR domain of OGT has been proposed to recognize substrate proteins via a concave surface lined by invariant asparagines, the most common residues at positions 6 and 9 in many TPR proteins ${ }^{36}$ (Fig. 5b).

In contrast to these TPR proteins, Nup358 ${ }^{\mathrm{NTD}}$ exhibits not only a markedly different topology of an open, extended, sheet-like conformation instead of the typical peptidebinding cradle, but it also lacks the canonical residues that are required for peptide recognition (Fig. 5b). Hence, Nup358 $8^{\mathrm{NTD}}$ appears poorly suited for binding extended peptide fragments in a carboxylate-clamp like fashion.

\section{Nup358 ${ }^{\mathrm{NTD}}$ binds to RNA in vitro}

Nup $358^{\text {NTD }}$ is not the only nucleoporin with an evolutionarily conserved strongly positive surface potential. Previously, we have shown that the Rae $1 \bullet$ Nup 98 GLEBS nucleoporin pair, another component of the cytoplasmic filaments of the NPC, possesses similar surface properties and is capable of binding single-stranded RNA in vitro. ${ }^{37}$ During the purification of Nup358 ${ }^{\mathrm{NTD}}$, we noticed the co-purification of endogenous bacterial RNA, as demonstrated by a digestion assay employing several DNA and RNA nucleases (Fig. 8a). Therefore, we analyzed whether Nup $358^{\mathrm{NTD}}$ is able to bind to a fluorescently labeled, decameric, degenerate, single-stranded RNA oligonucleotide using fluorescence anisotropy binding measurements. Indeed, we found that Nup358 $8^{\mathrm{NTD}}$ directly binds to single-stranded RNA with an apparent dissociation constant of $264 \pm 45 \mu \mathrm{M}$ in the presence of $5 \mathrm{mM} \mathrm{MgCl} 2$ (Fig. 8b). Together, these data indicate that Nup $358^{\mathrm{NTD}}$ possesses weak binding affinity for single-stranded RNA that is not solely explained by electrostatics. 


\section{In vivo analysis}

Nup358 is part of a nucleoporin subset that relocates to kinetochores after nuclear envelope breakdown. ${ }^{23}$ During interphase, Nup358 localizes to the cytoplasmic face of the NPC. ${ }^{9,10}$ To investigate whether the Nup358 NTD is required for NPC localization of Nup358, we analyzed the localization of a series of HA-tagged Nup358 constructs in HEK293T cells (Fig. 9). We found that full-length Nup358 and a Nup358 fragment that lacks the NTD (Nup358 ${ }^{\Delta \mathrm{NTD}}$ ) yield nuclear envelope rim staining that coincides with staining by mAb414, an antibody that recognizes a group of FG-repeat containing nucleoporins. ${ }^{38}$ In contrast, a Nup358 fragment that encompasses only the NTD is dispersed throughout the cell and does not enrich at the nuclear envelope. We conclude that the NTD is not required for nuclear envelope localization and dispensable for Nup358 anchoring to the cytoplasmic face of the NPC.

\section{Conclusions}

The N-terminal domain of Nup358 is composed of three central TPRs that are capped on both ends by solvating amphipathic ahelices. In contrast to other TPR domains, Nup358 NTD adopts an unusual extended, twisted sheet conformation with an evolutionarily conserved, highly positive surface potential that is incompatible with the canonical carboxylate-clamp mediated binding of short peptides, but facilitates the weak association with single-stranded RNA oligonucleotides. In vivo, the NTD is dispensable for nuclear envelope localization of Nup358.

What may be the physiological significance of the RNA binding property of Nup358 ${ }^{\text {NTD}}$ ? Nup358 is localized at the cytoplasmic face of the NPC, in close proximity to Nup214, and Nup88. Together, these two cytoplasmic filament nucleoporins play essential roles in the nuclear export of mRNA by providing critical binding platforms for several components of the mRNA export machinery, thereby recruiting them to the cytoplasmic face of the NPC. Specifically, Nup88 recruits the Nup98・Rae 1 complex, which also possesses weak singlestranded RNA binding activity, and Nup214 recruits the DEAD-box helicase Ddx19 and its ATPase-activating protein Gle1. ${ }^{14,17,18,37,39}$ The co-operation of Nup214 with Ddx19 and Gle1 has been proposed to result in the release of nuclear RNA binding proteins that cover the exported mRNA. ${ }^{8}$ Nup358 has been shown to provide a major binding site for the evolutionarily conserved mRNA export heterodimer p15•TAP at the cytoplasmic filaments of the NPC. ${ }^{19}$ Therefore, Nup $358^{\mathrm{NTD}}$ may be uniquely positioned to transiently interact and concentrate mRNPs at the cytoplasmic face of the NPC to speed their disassembly by Dbp5 or is involved in the export of other small RNA molecules, such as microRNPs, semiassembled snurps, or ribosomal subunits.

\section{Materials and Methods}

\section{Protein expression and purification}

The DNA fragment encoding the N-terminal domain of human and P. troglodytes Nup358 (residues 1-145) was amplified by PCR and inserted into the pGEX-6P1 expression vector (GE Healthcare) using BamHI and NotI restriction sites. The vector fuses an N-terminal glutathione- $S$-transferase (GST)-tag to the protein with a PreScission protease cleavage site 
directly after the GST-tag. Proteolytic cleavage leaves an additional five residues with the sequence GPLGS on the $\mathrm{N}$ terminus of Nup $358^{\mathrm{NTD}}$. Mutagenesis to produce the methionine mutants of $P$. troglodytes Nup358 ${ }^{\mathrm{NTD}}$, T27M, Y37M and T92M, was performed by Quikchange site-directed mutagenesis (Stratagene).

All Nup358 NTDs were expressed in E. coli BL21-CodonPlus(DE3)-RIL cells (Stratagene) that were grown in LB media containing appropriate antibiotics. Protein expression was induced at $\mathrm{OD}_{600}$ of $\approx 0.6$ with $450 \mu \mathrm{M}$ isopropyl- $\beta$-D-thiogalactoside at $18{ }^{\circ} \mathrm{C}$ for 14 hours. The cells were harvested by centrifugation and lysed with a cell disruptor (Avestin) in a buffer containing $20 \mathrm{mM}$ TRIS, pH 8.0, $500 \mathrm{mM} \mathrm{NaCl}, 5 \mathrm{mM} \beta$-mercaptoethanol ( $\beta$-ME), $0.5 \mathrm{mM}$ phenylmethylsulfonyl fluoride (Sigma), $2 \mu \mathrm{M}$ bovine lung aprotinin (Sigma), and complete EDTA-free protease inhibitor cocktail (Roche). After centrifugation at 40,000 $\times \mathrm{g}$ for $90 \mathrm{~min}$, the supernatant was filtered through a $0.22 \mu \mathrm{m}$ filter (Millipore), loaded onto a glutathione Sepharose 4B column (GE Healthcare) equilibrated in buffer A (20 mM TRIS, $\mathrm{pH}$ 8.0, $100 \mathrm{mM} \mathrm{NaCl}, 5 \mathrm{mM}$ DTT), and eluted with a linear gradient of buffer B (buffer A supplemented with $20 \mathrm{mM}$ glutathione). Protein-containing fractions were pooled and the GST-tag was cleaved with PreScission protease (GE Healthcare) during extensive dialysis against buffer A for 14 hours. The sample was then loaded onto a glutathione Sepharose 4B column to remove uncleaved protein, free GST, and GST-PreScission, and cleaved protein was collected in the flowthrough. After concentration, the protein was further purified by size exclusion chromatography on a Superdex 75 16/60 column (GE Healthcare) equilibrated in buffer A. Protein-containing fractions were pooled and concentrated to 10 $\mathrm{mg} / \mathrm{ml}$ for crystallization.

Seleno-L-methionine-labeled protein was produced in E. coli BL21-CodonPlus (DE3)-RIL cells (Stratagene) in a synthetic medium that suppresses methionine biosynthesis, following standard protocols. ${ }^{40}$

\section{Crystallization and data collection}

Initial crystals of Nup $358^{\mathrm{NTD}}$ were grown at $4{ }^{\circ} \mathrm{C}$ in $2 \mu \mathrm{l}$ hanging drops containing equal volumes of the protein solution and a reservoir solution consisting of $16-18 \%(\mathrm{w} / \mathrm{v})$ PEG 3,350 and $200 \mathrm{mM}$ lithium acetate. Large crystals were obtained by microseeding in $2.5 \mu \mathrm{l}$ hanging drops containing an additional $0.5 \mu \mathrm{l}$ seeding solution equilibrated against a reservoir solution consisting of 3-5 \% (w/v) PEG 3,350 and $200 \mathrm{mM}$ lithium acetate. Crystals appeared within hours and grew to a final size of approximately $1.0 \times 1.5 \times 1.0$ $\mathrm{mm}^{3}$ within a week. For cryoprotection, crystals were transferred in paraffin oil and flash frozen in liquid nitrogen. Native and anomalous X-ray diffraction data were collected at 100 $\mathrm{K}$ at beamline 12-2 at the Stanford Synchrotron Radiation Lightsource (SSRL). X-ray intensities were processed with the HKL2000 denzo/scalepack package. ${ }^{41}$

\section{Structure determination and refinement}

Phases were determined with SHARP, ${ }^{42}$ using X-ray diffraction data from crystals of a seleno-L-methionine-labeled $P$. troglodytes Nup $358^{\mathrm{NTD}}$ mutant in which three additional methionine-residues were incorporated at positions 27,37 , and 92 , followed by density modification in DM and Solomon (CCP4) ${ }^{43}$ with solvent flattening, histogram matching, 
and NCS averaging. Iterative model building and refinement were carried out with the programs $\mathrm{O},{ }^{44}$ Coot $,{ }^{45} \mathrm{CNS},{ }^{46}$ and PHENIX.${ }^{47}$ The final model of the P. troglodytes Nup $358^{\mathrm{NTD}}$ contains residues $2-145$ and was refined to $0.95-\AA \AA$ resolution with $\mathrm{R}_{\mathrm{work}}$ and $\mathrm{R}_{\text {free }}$ values of $18.2 \%$ and $20.9 \%$, respectively. The structure of the human Nup358 ${ }^{\mathrm{NTD}}$ was solved by molecular replacement in Phaser ${ }^{48}$, using the coordinates of the P. troglodytes Nup358 ${ }^{\text {NTD }}$ as the search model. The final model of the human Nup358 ${ }^{\mathrm{NTD}}$ contains residues 3-145 and was refined to 1.15 - $\AA$ resolution with $\mathrm{R}_{\text {work }}$ and $\mathrm{R}_{\text {free }}$ values of $23.6 \%$ and $25.6 \%$, respectively. The crystals of human Nup358 ${ }^{\mathrm{NTD}}$ are non-merohedrally twinned with orthorhombic unit cell dimensions of $a \approx 2 c$, and, thus, explain the higher $\mathrm{R}$ factors than expected for this resolution. ${ }^{49}$ The stereochemical quality of both models is excellent according to assessment with PROCHECK ${ }^{50}$ and MolProbity. ${ }^{51}$ For details of the data collection and refinement statistics, see Table 1.

\section{Analytical size-exclusion chromatography}

Analytical gel filtration experiments were carried out on a Superdex 200 10/300 GL gel filtration column (GE Healthcare) that was equilibrated in a buffer containing $20 \mathrm{mM}$ TRIS, $\mathrm{pH} 8.0,100 \mathrm{mM} \mathrm{NaCl}$, and $5 \mathrm{mM}$ DTT. $1 \mathrm{mg}$ of the purified Nup358 ${ }^{\mathrm{NTD}}$ was injected, and the elution volume monitored. Molecular weight standards (GE healthcare) were injected in identical buffer conditions and used for molecular mass determination.

\section{Multiangle light scattering}

Purified proteins were characterized by multi-angle light scattering following size exclusion chromatography. ${ }^{52}$ Protein at various concentrations $(50-100 \mu \mathrm{M})$ was injected onto a Superdex 200 10/300 GL gel filtration chromatography column (GE Healthcare) equilibrated in a buffer containing $20 \mathrm{mM}$ TRIS, pH 8.0, $100 \mathrm{mM} \mathrm{NaCl}$, and $5 \mathrm{mM}$ DTT. The chromatography system was connected in series with an 18-angle light scattering detector (DAWN HELEOS II, Wyatt Technology), a dynamic light scattering detector (DynaPro Nanostar, Wyatt Technology), and a refractive index detector (Optilab t-rEX, Wyatt Technology). Data was collected every 1 second at a flow rate of $0.5 \mathrm{~mL} / \mathrm{min}$ at $25^{\circ} \mathrm{C}$. Data analysis was carried out using the program ASTRA 6, yielding the molar mass and mass distribution (polydispersity) of the sample.

\section{Nuclease digests}

Nup358 ${ }^{\mathrm{NTD}} \cdot$ RNA complex was subjected to treatment with 1 unit each of DNase I (Roche), benzonase (VWR), RNase A (Qiagen), RNase T1 (Roche), and RNase V1 (Applied Biosystems), in a buffer containing $20 \mathrm{mM}$ TRIS, pH 8.0, $100 \mathrm{mM} \mathrm{NaCl}$, and $5 \mathrm{mM}$ DTT for $30 \mathrm{~min}$ at room temperature. The reactions were then separated on a $1.2 \%$ TRIS-acetateEDTA agarose gel and visualized by ethidium bromide staining.

\section{Fluorescence anisotropy}

Fluorescence anisotropy measurements were obtained using a Wallac 1420 Multilabel Counter plate reading instrument (Perkin Elmer) with a temperature controlled sample chamber at $25^{\circ} \mathrm{C}$. All fluorescence studies were carried out in $20 \mu \mathrm{l}$ volumes. Buffer conditions were $20 \mathrm{mM}$ TRIS, pH 8.0, $50 \mathrm{mM} \mathrm{KCl,} 5 \mathrm{mM} \mathrm{MgCl}_{2}, 2 \mathrm{mM}$ DTT, $10 \%$ (v/v) 
glycerol. Cy3-labeled degenerate, 10-mer RNA oligo-nucleotides at a final concentration of $100 \mathrm{nM}$ were incubated with varying concentrations $(100 \mathrm{nM}, 200 \mathrm{nM}, 500 \mathrm{nM}, 1 \mu \mathrm{M}, 1.5$ $\mu \mathrm{M}$, and $2 \mu \mathrm{M}$ ) of Nup358 ${ }^{\mathrm{NTD}}$. Raw data were fit using Prism 5.0 (GraphPad Software) with the non-linear equation for one site specific binding $\mathrm{Y}=(\mathrm{Bmax} * \mathrm{X} /(\mathrm{Kd}+\mathrm{X}))+$ background $)$ where $\mathrm{X}$ is the Nup358 ${ }^{\mathrm{NTD}}$ concentration, $\mathrm{Y}$ the change in anisotropy and Bmax the maximum change in anisotropy.

\section{Immunofluorescence microscopy}

For immunofluorescence, full-length Nup358 and Nup358 fragments (residues 1-3224, 1-145, and 146-3224) were inserted into the pCMV-HA vector (Clontech) using SalI and NotI restriction sites. The resulting Nup358 fragments contain a C-terminal HA-tag. HEK293T cells were grown on poly-L-lysine coated slides (Sigma) until 50 \% confluency. Transfection was performed with TransIT-LT1 transfection reagent (Mirus) according to the manufacturer's instructions. After 48 hours, the medium was removed and cells were washed in phosphate buffered saline (PBS) and fixed in PBS, supplemented with $2 \%(\mathrm{w} / \mathrm{v})$ formaldehyde for $5 \mathrm{~min}$ at room temperature. After two washes with PBS, the cells were permeabilized with PBS containing $0.1 \%$ (v/v) TritonX-100 (Sigma-Aldrich) for 10 minutes at room temperature. The cells were then washed in PBS and blocked in PBS supplemented with $10 \%$ (v/v) Fetal Calf Serum (FCS) for $20 \mathrm{~min}$ at room temperature. For nuclear envelope staining, the cells were incubated with a 1:500 dilution of the monoclonal antibody mAb414 (Abcam) in PBS buffer, supplemented with $0.1 \%(\mathrm{w} / \mathrm{v})$ saponin and $10 \%(\mathrm{v} / \mathrm{v})$ FCS for 16 hours at $4{ }^{\circ} \mathrm{C}$. Secondary antibody incubation was performed with a 1:3000 dilution of Alexa Fluor 568-labeled goat anti mouse antibody (Invitrogen) in PBS, supplemented with $0.1 \%(\mathrm{w} / \mathrm{v})$ saponin and $10 \%$ (v/v) FCS for 1 hour at room temperature, followed by three washes with PBS. For detection of the HA-tagged proteins, the cells were incubated with a monoclonal antibody anti-HA Fluor488 conjugate antibody (Invitrogen) for 1 hour at room temperature, washed three times with PBS, and mounted onto coverslips with ProLong Gold Antifade reagent with DAPI (Invitrogen). Slides were examined with fluorescence microscopy on a Carl Zeiss AxioImagerZ.1 equipped with an AxioCamMRm camera.

\section{Illustration and figures}

The sequence alignment of Nup358 ${ }^{\mathrm{NTD}}$ was generated using ClustalX $\mathrm{X}^{53}$ and colored with Alscript. ${ }^{54}$ Figures were generated using PyMOL (www.pymol.org), the electrostatic potential was calculated with APBS, ${ }^{55}$ and the inter-helical crossover angles were calculated with the program MOLMOL. 56

\section{Supplementary Material}

Refer to Web version on PubMed Central for supplementary material.

\section{ACKNOWLEDGEMENTS}

We thank Erik Debler, Martin Jinek, and Alina Patke for critical reading of the manuscript, Stephanie Etherton for help with editing of the manuscript, Evelyn Stuwe for help with fluorescence microscopy, David King for mass spectrometry analysis, and the Berger laboratory for use of their spectrometer for fluorescence anisotropy. We thank Jens Kaiser and the scientific staff of SSRL beamline 12-2 for their support with X-ray diffraction measurements. 
We acknowledge the Gordon and Betty Moore Foundation for their support of the Molecular Observatory at the California Institute of Technology. The operations at the SSRL are supported by the Department of Energy and by the National Institutes of Health. SK was supported by a fellowship of the German National Academic Foundation, JN was supported by a fellowship of the Women in Science Foundation, and AH was supported by a SCOR grant from the Leukemia and Lymphoma Society, the Albert Wyrick V Scholar Award of the V Foundation for Cancer Research, the $54^{\text {th }}$ Mallinckrodt Scholar Award of the Edward Mallinckrodt, Jr. Foundation, and a Kimmel Scholar Award of the Sidney Kimmel Foundation for Cancer Research.

\section{References}

1. Hoelz A, Debler EW, Blobel G. The structure of the nuclear pore complex. Annu. Rev. Biochem. 2011; 80:613-43. [PubMed: 21495847]

2. Debler EW, Hsia KC, Nagy V, Seo HS, Hoelz A. Characterization of the membrane-coating Nup84 complex: Paradigm for the nuclear pore complex structure. Nucleus. 2010; 1:150-157. [PubMed: 21326946]

3. Debler EW, Ma Y, Seo HS, Hsia KC, Noriega TR, Blobel G, Hoelz A. A fence-like coat for the nuclear pore membrane. Mol. Cell. 2008; 32:815-26. [PubMed: 19111661]

4. Hsia KC, Stavropoulos P, Blobel G, Hoelz A. Architecture of a coat for the nuclear pore membrane. Cell. 2007; 131:1313-26. [PubMed: 18160040]

5. Brohawn SG, Leksa NC, Spear ED, Rajashankar KR, Schwartz TU. Structural evidence for common ancestry of the nuclear pore complex and vesicle coats. Science. 2008; 322:1369-73. [PubMed: 18974315]

6. Fath S, Mancias JD, Bi X, Goldberg J. Structure and organization of coat proteins in the COPII cage. Cell. 2007; 129:1325-36. [PubMed: 17604721]

7. Lee C, Goldberg J. Structure of coatomer cage proteins and the relationship among COPI, COPII, and clathrin vesicle coats. Cell. 2010; 142:123-32. [PubMed: 20579721]

8. Stewart M. Ratcheting mRNA out of the nucleus. Mol. Cell. 2007; 25:327-30. [PubMed: 17289581]

9. Wu J, Matunis MJ, Kraemer D, Blobel G, Coutavas E. Nup358, a cytoplasmically exposed nucleoporin with peptide repeats, Ran-GTP binding sites, zinc fingers, a cyclophilin A homologous domain, and a leucine-rich region. J. Biol. Chem. 1995; 270:14209-13. [PubMed: 7775481]

10. Yokoyama N, Hayashi N, Seki T, Pante N, Ohba T, Nishii K, Kuma K, Hayashida T, Miyata T, Aebi U, et al. A giant nucleopore protein that binds Ran/TC4. Nature. 1995; 376:184-8. [PubMed: 7603572]

11. Cook A, Bono F, Jinek M, Conti E. Structural biology of nucleocytoplasmic transport. Annu. Rev. Biochem. 2007; 76:647-71. [PubMed: 17506639]

12. Gleizes PE, Noaillac-Depeyre J, Leger-Silvestre I, Teulieres F, Dauxois JY, Pommet D, AzumGelade MC, Gas N. Ultrastructural localization of rRNA shows defective nuclear export of preribosomes in mutants of the Nup82p complex. J. Cell. Biol. 2001; 155:923-36. [PubMed: 11739405]

13. Powers MA, Forbes DJ, Dahlberg JE, Lund E. The vertebrate GLFG nucleoporin, Nup98, is an essential component of multiple RNA export pathways. J. Cell Biol. 1997; 136:241-50. [PubMed: 9015297]

14. Stuwe T, Schada von Borzyskowski L, Davenport AM, Hoelz A. Molecular basis for the anchoring of proto-oncoprotein nup98 to the cytoplasmic face of the nuclear pore complex. J. Mol. Biol. 2012; 419:330-46. [PubMed: 22480613]

15. Yoshida K, Seo HS, Debler EW, Blobel G, Hoelz A. Structural and functional analysis of an essential nucleoporin heterotrimer on the cytoplasmic face of the nuclear pore complex. Proc. Natl. Acad. Sci. USA. 2011; 108:16571-6. [PubMed: 21930948]

16. Schmitt C, von Kobbe C, Bachi A, Pante N, Rodrigues JP, Boscheron C, Rigaut G, Wilm M, Seraphin B, Carmo-Fonseca M, Izaurralde E. Dbp5, a DEAD-box protein required for mRNA export, is recruited to the cytoplasmic fibrils of nuclear pore complex via a conserved interaction with CAN/Nup159p. EMBO J. 1999; 18:4332-47. [PubMed: 10428971]

17. Napetschnig J, Kassube SA, Debler EW, Wong RW, Blobel G, Hoelz A. Structural and functional analysis of the interaction between the nucleoporin Nup214 and the DEAD-box helicase Ddx19. Proc. Natl. Acad. Sci. USA. 2009; 106:3089-94. [PubMed: 19208808] 
18. von Moeller H, Basquin C, Conti E. The mRNA export protein DBP5 binds RNA and the cytoplasmic nucleoporin NUP214 in a mutually exclusive manner. Nat. Struct. Mol. Biol. 2009; 16:247-54. [PubMed: 19219046]

19. Forler D, Rabut G, Ciccarelli FD, Herold A, Kocher T, Niggeweg R, Bork P, Ellenberg J, Izaurralde E. RanBP2/Nup358 provides a major binding site for NXF1-p15 dimers at the nuclear pore complex and functions in nuclear mRNA export. Mol. Cell. Biol. 2004; 24:1155-67. [PubMed: 14729961]

20. Matunis MJ, Wu J, Blobel G. SUMO-1 modification and its role in targeting the Ran GTPaseactivating protein, RanGAP1, to the nuclear pore complex. J. Cell Biol. 1998; 140:499-509. [PubMed: 9456312]

21. Bernad R, van der Velde H, Fornerod M, Pickersgill H. Nup358/RanBP2 attaches to the nuclear pore complex via association with Nup88 and Nup214/CAN and plays a supporting role in CRM1mediated nuclear protein export. Mol. Cell. Biol. 2004; 24:2373-84. [PubMed: 14993277]

22. Joseph J, Dasso M. The nucleoporin Nup358 associates with and regulates interphase microtubules. FEBS Lett. 2008; 582:190-6. [PubMed: 18070602]

23. Salina D, Enarson P, Rattner JB, Burke B. Nup358 integrates nuclear envelope breakdown with kinetochore assembly. J. Cell Biol. 2003; 162:991-1001. [PubMed: 12963708]

24. Slape C, Aplan PD. The role of NUP98 gene fusions in hematologic malignancy. Leuk. Lymphoma. 2004; 45:1341-50. [PubMed: 15359631]

25. Kohler A, Hurt E. Gene regulation by nucleoporins and links to cancer. Mol. Cell. 2010; 38:6-15. [PubMed: 20385085]

26. Agudo D, Gomez-Esquer F, Martinez-Arribas F, Nunez-Villar MJ, Pollan M, Schneider J. Nup88 mRNA overexpression is associated with high aggressiveness of breast cancer. Int. J. Cancer. 2004; 109:717-20. [PubMed: 14999780]

27. Felix RS, Colleoni GW, Caballero OL, Yamamoto M, Almeida MS, Andrade VC, Chauffaille Mde L, Silva WA Jr. Begnami MD, Soares FA, Simpson AJ, Zago MA, Vettore AL. SAGE analysis highlights the importance of p53csv, ddx5, mapkapk2 and ranbp2 to multiple myeloma tumorigenesis. Cancer Lett. 2009; 278:41-8. [PubMed: 19171422]

28. von Lindern M, Fornerod M, van Baal S, Jaegle M, de Wit T, Buijs A, Grosveld G. The translocation $(6 ; 9)$, associated with a specific subtype of acute myeloid leukemia, results in the fusion of two genes, dek and can, and the expression of a chimeric, leukemia-specific dek-can mRNA. Mol. Cell. Biol. 1992; 12:1687-97. [PubMed: 1549122]

29. Ma Z, Hill DA, Collins MH, Morris SW, Sumegi J, Zhou M, Zuppan C, Bridge JA. Fusion of ALK to the Ran-binding protein 2 (RANBP2) gene in inflammatory myofibroblastic tumor. Genes Chromosomes Cancer. 2003; 37:98-105. [PubMed: 12661011]

30. Neilson DE, Adams MD, Orr CM, Schelling DK, Eiben RM, Kerr DS, Anderson J, Bassuk AG, Bye AM, Childs AM, Clarke A, Crow YJ, Di Rocco M, Dohna-Schwake C, Dueckers G, Fasano AE, Gika AD, Gionnis D, Gorman MP, Grattan-Smith PJ, Hackenberg A, Kuster A, Lentschig MG, Lopez-Laso E, Marco EJ, Mastroyianni S, Perrier J, Schmitt-Mechelke T, Servidei S, Skardoutsou A, Uldall P, van der Knaap MS, Goglin KC, Tefft DL, Aubin C, de Jager P, Hafler D, Warman ML. Infection-triggered familial or recurrent cases of acute necrotizing encephalopathy caused by mutations in a component of the nuclear pore, RANBP2. Am. J. Hum. Genet. 2009; 84:44-51. [PubMed: 19118815]

31. Chook YM, Blobel G. Karyopherins and nuclear import. Curr. Opin. Struct. Biol. 2001; 11:70315. [PubMed: 11751052]

32. Blatch GL, Lassle M. The tetratricopeptide repeat: a structural motif mediating protein-protein interactions. Bioessays. 1999; 21:932-9. [PubMed: 10517866]

33. D'Andrea LD, Regan L. TPR proteins: the versatile helix. Trends Biochem. Sci. 2003; 28:655-62. [PubMed: 14659697]

34. Das AK, Cohen PW, Barford D. The structure of the tetratricopeptide repeats of protein phosphatase 5: implications for TPR-mediated protein-protein interactions. EMBO J. 1998; 17:1192-9. [PubMed: 9482716] 
35. Scheufler C, Brinker A, Bourenkov G, Pegoraro S, Moroder L, Bartunik H, Hartl FU, Moarefi I. Structure of TPR domain-peptide complexes: critical elements in the assembly of the Hsp70Hsp90 multichaperone machine. Cell. 2000; 101:199-210. [PubMed: 10786835]

36. Jinek M, Rehwinkel J, Lazarus BD, Izaurralde E, Hanover JA, Conti E. The superhelical TPRrepeat domain of O-linked GlcNAc transferase exhibits structural similarities to importin alpha. Nat. Struct. Mol. Biol. 2004; 11:1001-7. [PubMed: 15361863]

37. Ren Y, Seo HS, Blobel G, Hoelz A. Structural and functional analysis of the interaction between the nucleoporin Nup98 and the mRNA export factor Rae1. Proc. Natl. Acad. Sci. USA. 2010; 107:10406-11. [PubMed: 20498086]

38. Davis LI, Blobel G. Identification and characterization of a nuclear pore complex protein. Cell. 1986; 45:699-709. [PubMed: 3518946]

39. Montpetit B, Thomsen ND, Helmke KJ, Seeliger MA, Berger JM, Weis K. A conserved mechanism of DEAD-box ATPase activation by nucleoporins and InsP6 in mRNA export. Nature. 2011; 472:238-42. [PubMed: 21441902]

40. Doublie S. Preparation of selenomethionyl proteins for phase determination. Methods Enzymol. 1997; 276:523-30.

41. Otwinowski Z, Minor W. Processing of X-ray diffraction data collected in oscillation mode. Methods Enzymol. 1997; 276:307-26.

42. Bricogne G, Vonrhein C, Flensburg C, Schiltz M, Paciorek W. Generation, representation and flow of phase information in structure determination: recent developments in and around SHARP 2.0. Acta Crystallogr. D Biol. Crystallogr. 2003; 59:2023-30. [PubMed: 14573958]

43. CCP4. The CCP4 Suite: Programs for Protein Crystallography. Acta Crystallogr. D Biol. Crystallogr. 1994; 50:760-763. [PubMed: 15299374]

44. Jones TA, Zou JY, Cowan SW, Kjeldgaard M. Improved methods for building protein models in electron density maps and the location of errors in these models. Acta Crystallogr. A. 1991; 47(Pt 2):110-9. [PubMed: 2025413]

45. Emsley P, Cowtan K. Coot: model-building tools for molecular graphics. Acta Crystallogr. D Biol. Crystallogr. 2004; 60:2126-32. [PubMed: 15572765]

46. Brunger AT, Adams PD, Clore GM, DeLano WL, Gros P, Grosse-Kunstleve RW, Jiang JS, Kuszewski J, Nilges M, Pannu NS, Read RJ, Rice LM, Simonson T, Warren GL. Crystallography \& NMR system: A new software suite for macromolecular structure determination. Acta Crystallogr. D Biol. Crystallogr. 1998; 54:905-21. [PubMed: 9757107]

47. Adams PD, Afonine PV, Bunkoczi G, Chen VB, Davis IW, Echols N, Headd JJ, Hung LW, Kapral GJ, Grosse-Kunstleve RW, McCoy AJ, Moriarty NW, Oeffner R, Read RJ, Richardson DC, Richardson JS, Terwilliger TC, Zwart PH. PHENIX: a comprehensive Python-based system for macromolecular structure solution. Acta Crystallogr. D Biol. Crystallogr. 2010; 66:213-21. [PubMed: 20124702]

48. McCoy AJ, Grosse-Kunstleve RW, Adams PD, Winn MD, Storoni LC, Read RJ. Phaser crystallographic software. J. Appl. Crystallogr. 2007; 40:658-674. [PubMed: 19461840]

49. Parsons S. Introduction to twinning. Acta Crystallogr. D Biol. Crystallogr. 2003; 59:1995-2003. [PubMed: 14573955]

50. Laskowski RA, MacArthur MW, Moss DS, Thornton JM. PROCHECK - a program to check the stereochemical quality of protein structures. J. Appl. Crystallogr. 1993; 26:283-291.

51. Davis IW, Leaver-Fay A, Chen VB, Block JN, Kapral GJ, Wang X, Murray LW, Arendall WB 3rd, Snoeyink J, Richardson JS, Richardson DC. MolProbity: all-atom contacts and structure validation for proteins and nucleic acids. Nucleic Acids Res. 2007; 35:W375-83. [PubMed: 17452350]

52. Wyatt PJ. Multiangle light scattering: The basic tool for macromolecular characterization. Instrum. Sci. Technol. 1997; 25:1-18.

53. Jeanmougin F, Thompson JD, Gouy M, Higgins DG, Gibson TJ. Multiple sequence alignment with Clustal X. Trends Biochem. Sci. 1998; 23:403-5. [PubMed: 9810230]

54. Barton GJ. ALSCRIPT: a tool to format multiple sequence alignments. Protein Eng. 1993; 6:3740. [PubMed: 8433969] 
55. Baker NA, Sept D, Joseph S, Holst MJ, McCammon JA. Electrostatics of nanosystems: application to microtubules and the ribosome. Proc. Natl. Acad. Sci. USA. 2001; 98:10037-10041. [PubMed: 11517324]

56. Koradi R, Billeter M, Wuthrich K. MOLMOL: a program for display and analysis of macromolecular structures. J. Mol. Graph. 1996; 14:51-5. 29-32. [PubMed: 8744573]

57. Main ER, Xiong Y, Cocco MJ, D'Andrea L, Regan L. Design of stable alpha-helical arrays from an idealized TPR motif. Structure. 2003; 11:497-508. [PubMed: 12737816] 


\section{Highlights}

1. Crystal structure of the N-terminal TPR domain of Nup358 at atomic resolution

2. Nup358 N-terminal domain possesses single-stranded RNA binding capacity

3. Nup358 N-terminal domain is dispensable for Nup358 nuclear envelope localization 


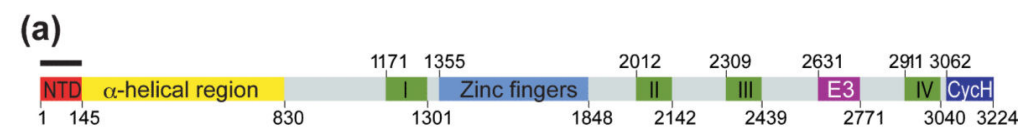

(b)

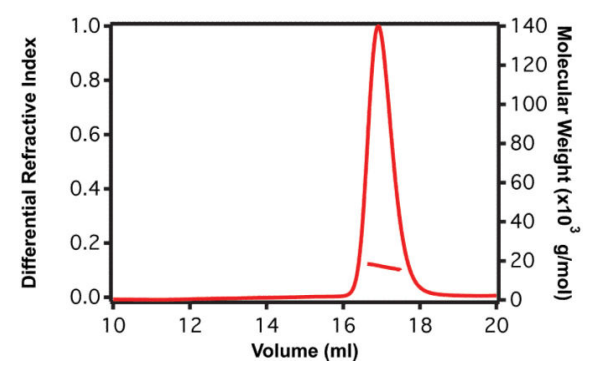

Fig. 1.

Biochemical and biophysical analysis of Nup358 ${ }^{\mathrm{NTD}}$. (a) Domain organization of human Nup358. Domain boundaries are indicated by residue numbers. The bar above the domain structure denotes the crystallized fragment. I, II, III, and IV, Ran binding domains; NTD, Nterminal domain; $\mathrm{CycH}$, cyclophilin homology domain; E3, E3 ligase domain. (b) Multiangle light-scattering (MALS) analysis of the P. troglodytes Nup358 ${ }^{\mathrm{NTD}}$. The differential refractive index is plotted against the elution volumes from a Superdex 200 $10 / 300$ GL gel-filtration column and is overlaid with the determined molecular mass. 

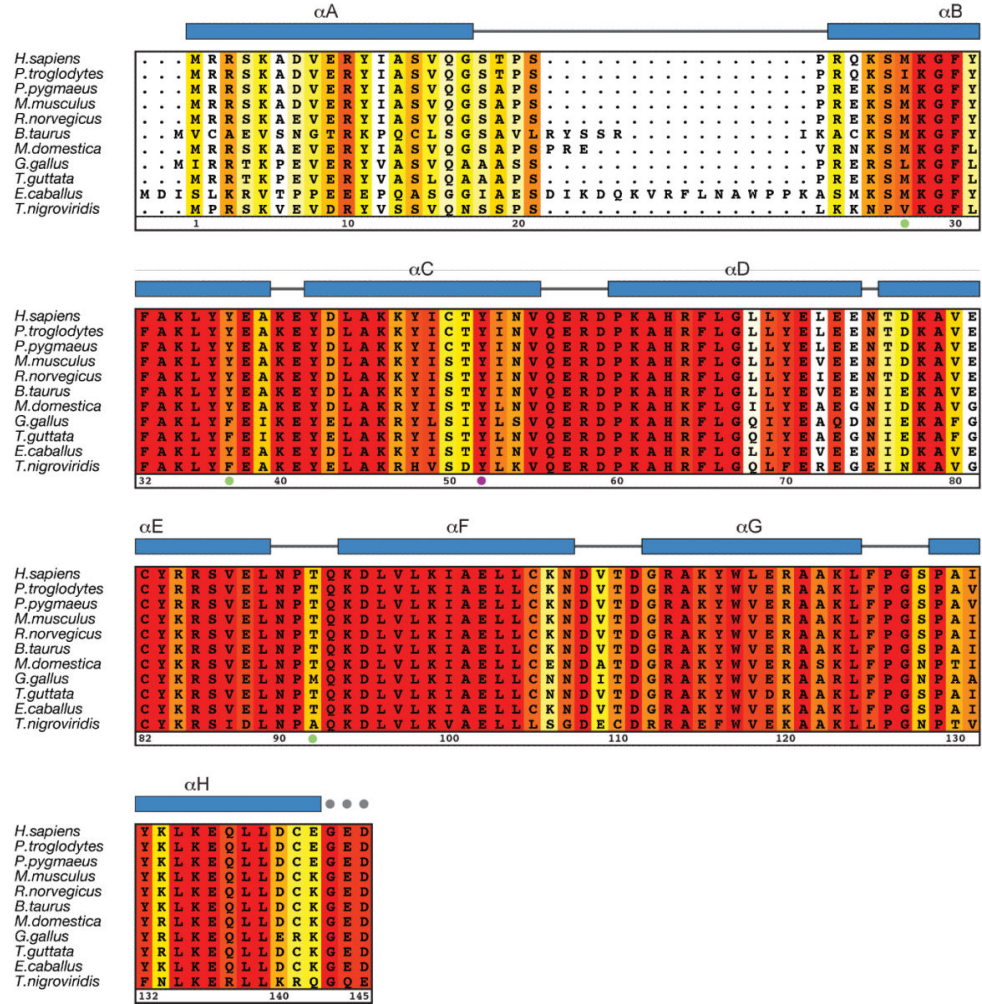

Fig. 2.

Multi-species sequence alignment of Nup358 ${ }^{\mathrm{NTD}}$. The overall sequence conservation is shaded from white (less than $60 \%$ similarity) to red (100\% identity) and has been calculated based on the Blosum62 algorithm. The secondary structure as observed in Nup $358^{\text {NTD }}$ structure is shown above the alignment, with blue bars representing a helices. The numbering below the sequence is relative to human Nup358. The positions of the introduced methinonine mutants and Y52 are indicated by green and purple dots, respectively. 
(a)

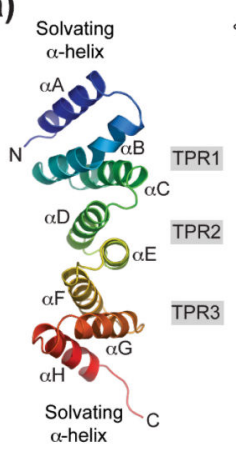

(b)

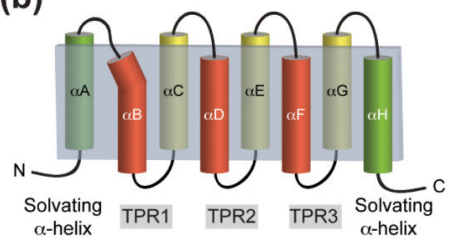

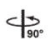

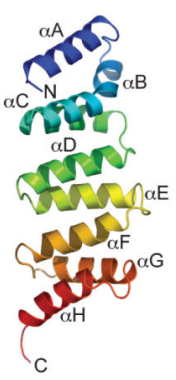

(c)

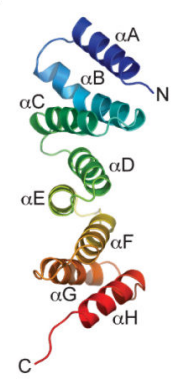

$\varphi_{90^{\circ}}$
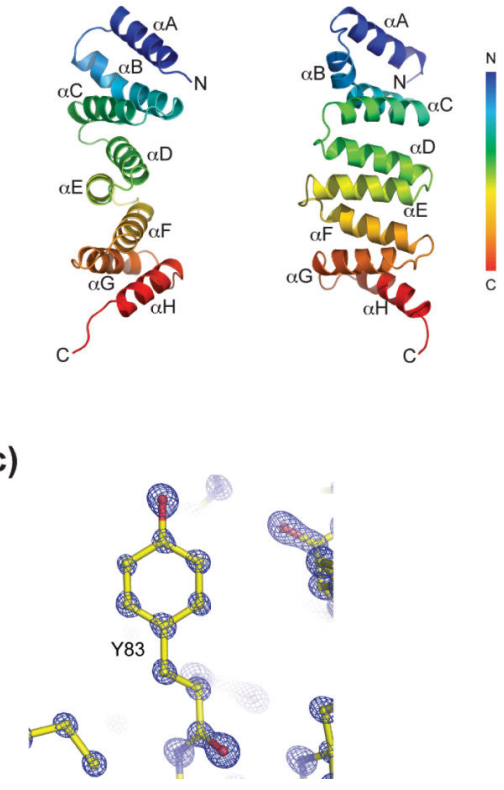

Fig. 3.

Structure of the NTD of Nup358. (a) Ribbon representation of Nup358 NTD shown in rainbow colors from the $\mathrm{N}$ - to the $\mathrm{C}$-terminus (aA to $\mathrm{aH}$ ). Views rotated by $90^{\circ}, 180^{\circ}$, and $270^{\circ}$ are shown on the right. (b) Schematic drawing showing the structural organization of Nup358 NTD. The a helices of the three centrally positioned TPR repeats form two layers, one on the concave $(\mathrm{aB}, \mathrm{aD}$, and $\mathrm{aF})$ and one on the convex side $(\mathrm{aC}, \mathrm{aE}$, and $\mathrm{aG})$ of the domain. The TPRs are capped by solvating a helices on both termini. (c) Representative final 2 |fo|-|fc| electron density maps, rendered at $5.0 \mathrm{\sigma}$. 
(a)
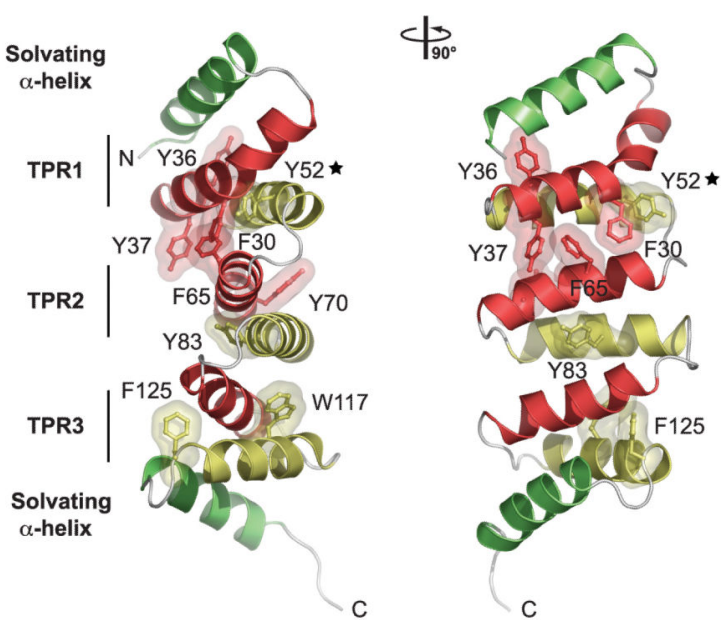

(b)

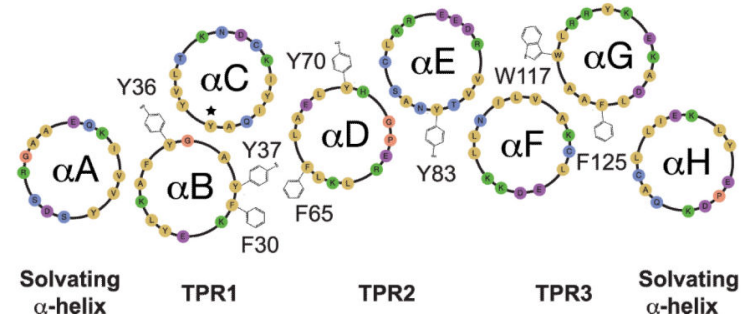

Fig. 4.

The non-canonical conformation of Nup358 ${ }^{\mathrm{NTD}}$ is induced by bulky hydrophobic side chains. (a) Cartoon representation of Nup358 ${ }^{\mathrm{NTD}}$ with selected side chains shown in ball and stick. A $90^{\circ}$-rotated view is shown on the right. (b) Helical wheel representation of the Nup358 $8^{\text {NTD }}$ with selected hydrophobic side chains drawn. The star denotes the position of the conserved Tyr52 in helix aC that induces the kink in helix aB. 
(a)

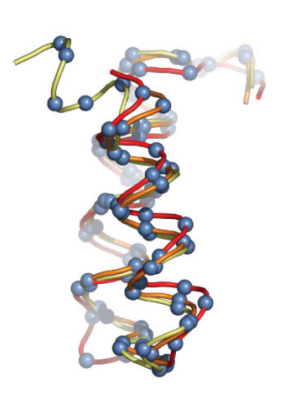

4

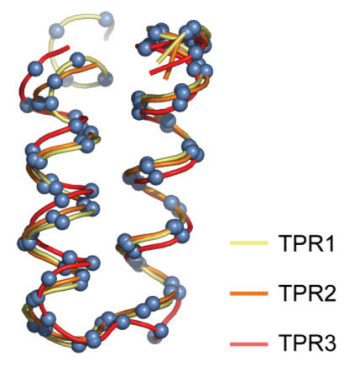

(b)

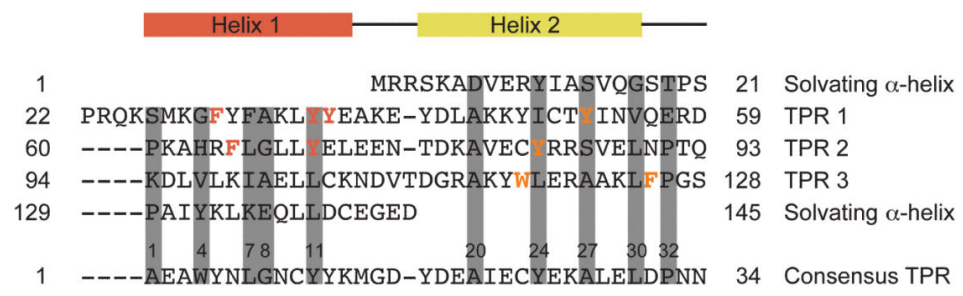

Fig. 5.

The TPR motif of Nup $358^{\mathrm{NTD}}$. (a) Superposition of the three TPRs of Nup358 $8^{\mathrm{NTD}}$. The positions of the $\mathrm{Ca}$ atoms are shown as blue spheres. $\mathrm{A} 90^{\circ}$-rotated view is shown on the right. The three TPRs align well with the exception of the kinked a helix aB of TPR1, and the $\mathrm{aF}-\mathrm{aG}$ loop of TPR3, which is one residue longer than in a canonical TPR. (b) Structure-based sequence alignment of the three TPRs and the two solvating a helices. The sequence of the consensus TPR is shown at the bottom of the alignment and is based on the analysis by Main and coworkers. ${ }^{57}$ The position of the a helices and the connecting loops relative to the consensus sequence is indicated at the top. Conserved small and large hydrophobic residues are highlighted with grey bars; large hydrophobic side chains are highlighted in orange. 
(a)

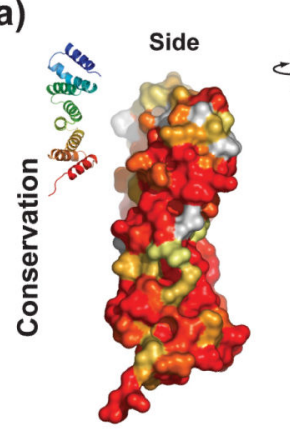

(b)

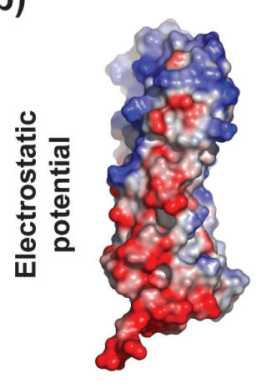

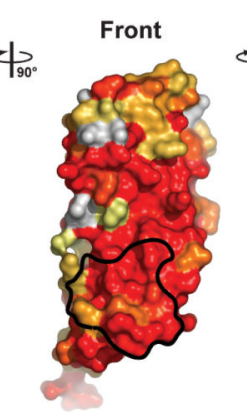
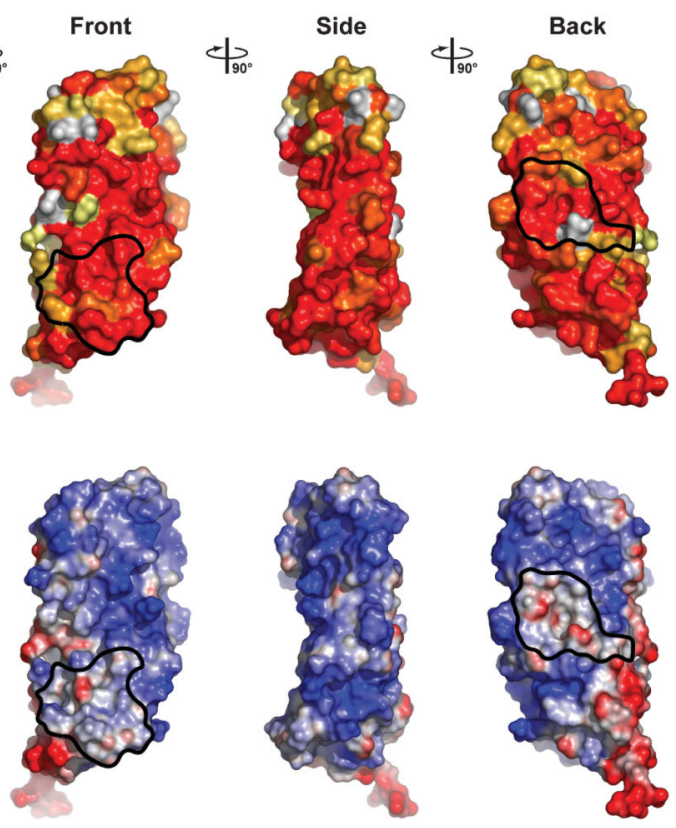

Fig. 6.

Surface properties of Nup358 ${ }^{\mathrm{NTD}}$. (a) Surface representation illustrating the surface conservation. The surface is colored according to a multi-species sequence alignment (Fig. 2). The conservation at each position is mapped onto the surface and is shaded in a color gradient from white (60\% similarity) to red (100\% identity). (b) Surface rendition colored according to the electrostatic potential from $-5 \mathrm{k}_{\mathrm{B}} \mathrm{T} / \mathrm{e}$ (red) to $+5 \mathrm{k}_{\mathrm{B}} \mathrm{T} / \mathrm{e}$ (blue). Black lines indicate the borders of the two evolutionarily conserved hydrophobic patches. 

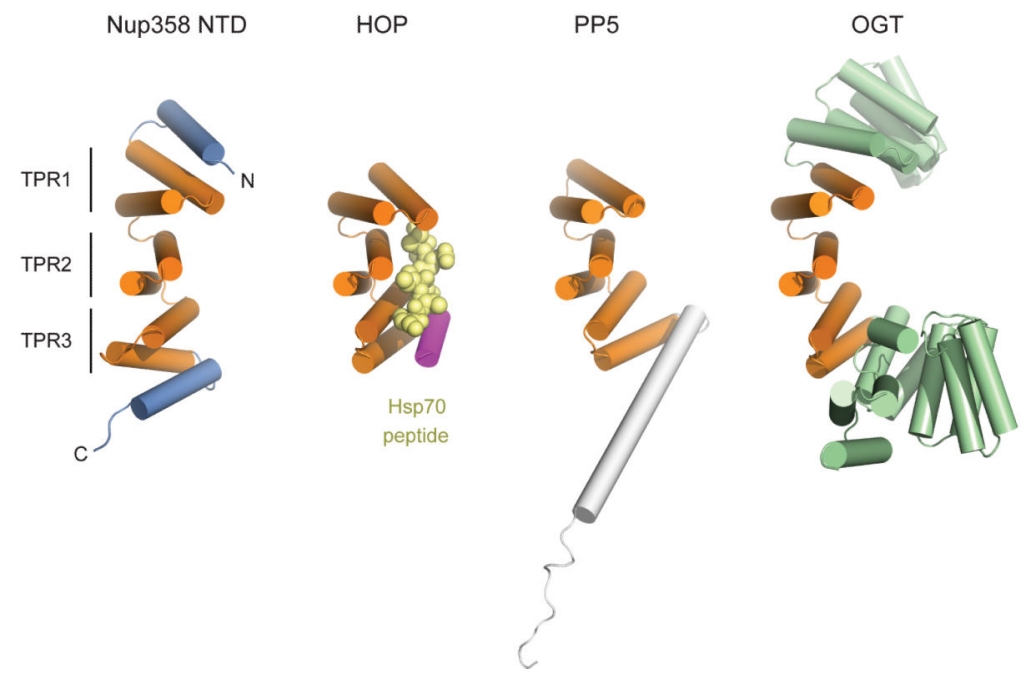

Fig. 7.

Comparison of Nup358 ${ }^{\mathrm{NTD}}$ to other TPR proteins. The three central TPR repeats of (A) Nup358 ${ }^{\mathrm{NTD}}$, (B) the TPR1 domain of Hop in complex with an Hsp70 peptide (PDB code 1ELW), (C) the TPR domain of protein phosphatase 5 (PDB code 1A17), and (D) the TPR domain of O-linked GlcNAc transferase (PDB code 1W3B) are illustrated. Equivalent TPRs are colored in orange. The Hsp70 peptide bound to the TPR1 domain of Hop is shown in yellow. Nup $358^{\mathrm{NTD}}$ adopts a substantially shallower conformation as compared to the other TPR proteins. 
(a)

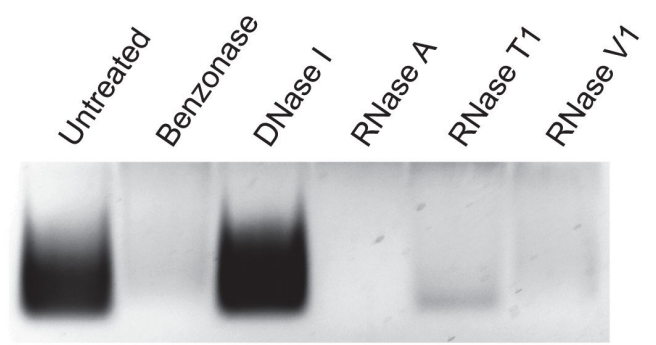

(b)

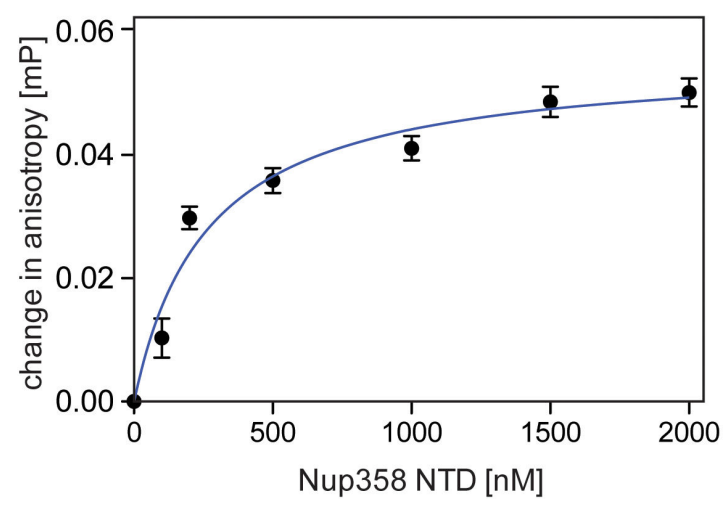

Fig. 8.

Nup358 NTD interacts with single-stranded RNA. (a) Nup358 NTD co-purifies with $E$. coli RNA. Purified Nup358 ${ }^{\text {NTD }} \cdot$ RNA was subjected to various DNA and RNA nuclease digests. (b) Association of Nup358 ${ }^{\mathrm{NTD}}$ with fluorescently-labeled, single-stranded, degenerate, decameric RNA oligo-nucleotide. Fluorescence polarization reveals an apparent dissociation constant (Kd) of $264 \pm 45 \mu \mathrm{M}$ between Nup358 ${ }^{\mathrm{NTD}}$ and a Cy3-labeled degenerate, decameric, single-stranded RNA oligonucleotide. The mean of three experiments each measured three times are represented, error bars represent the SEM (standard error of the mean). 


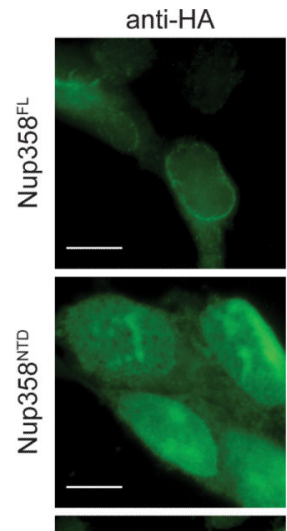

mAb414
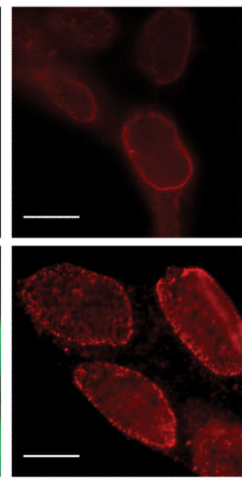

0
5
5
0
0
0
0
$z$
$z$

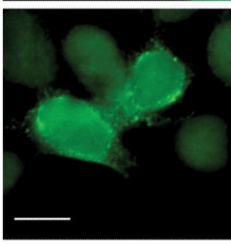

DAPI
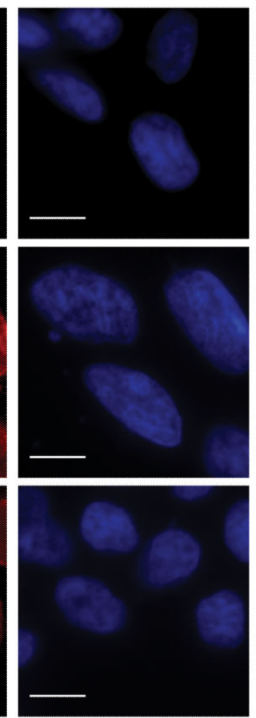

merge
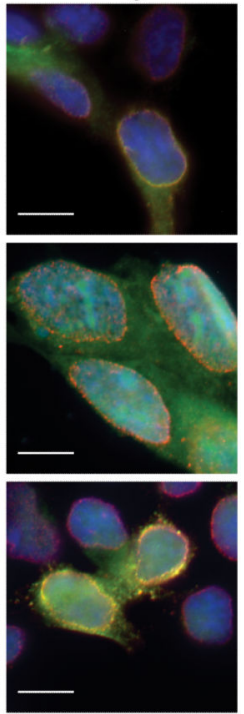

Fig 9.

In vivo localization of full-length Nup358 and Nup358 fragments. HEK293T cells were transfected with Nup358 and Nup358 fragments containing a C-terminal HA-tag and analyzed by fluorescence microscopy. The cellular localization of the HA-tagged Nup358 proteins was detected with an a-HA antibody (green). The monoclonal a-mAb414 antibody (red) and DAPI (blue) were used as a reference for nuclear envelope and nucleus staining, respectively. The merged image is shown on the right. 


\section{Table 1}

Crystallographic Analysis

\begin{tabular}{|c|c|c|c|}
\hline & Pan troglodytes SeMet & Pan troglodytes Native & Homo sapiens Native \\
\hline \multicolumn{4}{|l|}{ Data collection } \\
\hline Protein & ptNup358 ${ }^{\mathrm{NTD}}$ T27M Y37M T92M & ptNup358 $8^{\text {NTD }}$ & toNup358 $8^{\text {NTD }}$ \\
\hline Synchrotron & $\operatorname{SSRL}^{a}$ & SSRL & SSRL \\
\hline Beamline & BL12-2 & BL12-2 & BL12-2 \\
\hline Space group & $\mathrm{P} 2{ }_{1} 2{ }_{1} 2$ & $\mathrm{P} 22_{1} 2$ & $\mathrm{P} 22_{1} 2$ \\
\hline \multicolumn{4}{|l|}{ Cell parameters } \\
\hline$a, b, c(\AA)$ & $a=58.4, b=83.6, c=30.0$ & $a=58.8, b=83.2, c=29.6$ & $\mathrm{a}=59.2, \mathrm{~b}=82.8, \mathrm{c}=29.5$ \\
\hline \multirow[t]{2}{*}{$\mathrm{a}, \beta, \gamma\left({ }^{\circ}\right)$} & $a=\beta=\gamma=90.0$ & $a=\beta=\gamma=90.0$ & $a=\beta=\gamma=90.0$ \\
\hline & Se Peak & & \\
\hline Wavelength $(\AA)$ & 0.9795 & 0.7500 & 1.0332 \\
\hline Resolution $(\AA)$ & $50.0-1.15$ & $50.0-0.95$ & $50.0-1.15$ \\
\hline$R_{\mathrm{sym}}(\%)^{b}$ & $6.7(52.7)$ & $6.5(79.8)$ & $4.5(78.7)$ \\
\hline$<|>|<\sigma /\rangle^{b}$ & $21.9(3.1)$ & $35.2(1.4)$ & $60.5(1.7)$ \\
\hline Completeness $(\%)^{b}$ & $98.6(93.1)$ & $99.6(98.7)$ & 96.7 (76.6) \\
\hline No. observations & $2,054,575$ & $5,334,428$ & $2,304,141$ \\
\hline No. unique reflections & $99,589(9,396)$ & $91,707(8,956)$ & $50,873(3,967)$ \\
\hline Redundancy & $6.3(4.4)$ & $12.2(9.6)$ & $15.6(7.8)$ \\
\hline Phasing power & 2.093 & & \\
\hline \multicolumn{4}{|l|}{ Refinement } \\
\hline Resolution $(\AA)$ & $50.0-1.15$ & $50.0-0.95$ & $50.0-1.15$ \\
\hline No. reflections total & 99,449 & 91,604 & 50,201 \\
\hline No. reflections test set & $5,019(5.05 \%)$ & $4,588(5.01 \%)$ & $2,565(5.11 \%)$ \\
\hline$R_{\text {work }} / R_{\text {free }}$ & $19.3 / 22.3$ & $17.7 / 19.9$ & $21.4 / 23.9$ \\
\hline No. atoms & 2,650 & 3,299 & 2,854 \\
\hline Protein & 2,419 & 3,027 & 2,767 \\
\hline Water & 231 & 267 & 85 \\
\hline \multicolumn{4}{|l|}{$B$-factors } \\
\hline Protein & 24.2 & 18.4 & 29.3 \\
\hline Water & 33.7 & 32.9 & 34.7 \\
\hline \multicolumn{4}{|l|}{ R.m.s. deviations } \\
\hline Bond lengths $(\AA)$ & 0.013 & 0.009 & 0.006 \\
\hline Bond angles $\left({ }^{\circ}\right)$ & 1.4 & 1.3 & 1.1 \\
\hline \multicolumn{4}{|l|}{ Ramachandran plot ${ }^{c}$} \\
\hline Favored $(\%)$ & 97.9 & 96.5 & 97.9 \\
\hline Additionally allowed (\%) & 2.1 & 3.5 & 2.1 \\
\hline Outliers (\%) & 0.0 & 0.0 & 0.0 \\
\hline MolProbity score & 1.28 & 1.61 & 1.58 \\
\hline
\end{tabular}

J Mol Biol. Author manuscript; available in PMC 2014 November 10. 
${ }^{a}$ SSRL, Stanford Synchrotron Radiation Lightsource

$b_{\text {Highest-resolution shell is shown in parentheses }}$

${ }^{c}$ As determined by MolProbity 51 